\title{
The Current Status Quo and Development of Inclusive Education in Canada and its Enlightenment
}

\author{
Han Honggang \\ Weinan Normal University, Weinan 714099, China
}

Keywords: The inclusive education; characteristic; enlightenment

\begin{abstract}
Inclusive education is first stated in the early 1990s. The concepts of inclusive education increasingly are developed by all countries. Many countries have carried out the policies of inclusive education and in different degree of inclusive education work. Although many areas in China have begun to implement inclusive education measures, the development of inclusive education in our country is still in the bud. In the university education still exist in the traditional teaching concept. Society's understanding of inclusive education view and opinions vary, even there exist objections. Inclusive education, as a kind of new trend of international education and inclusive education, is the trend of the development of the education in the 21st century. Therefore, one must conform to the trend of globalization of education and strengthen the research and spread of inclusive education thought. The inclusive education of Canada is focused on kinds of students with special educational needs and cooperation learning as the characteristics. Canada and China are both similar in multiple nationalities, multicultural country, especially in terms of education. Firstly, the writer concentrated on Canadian inclusive education development present situation as the research object, and then draws lessons from the development characteristic of inclusive education in Canada; thirdly, the author analyzes the situation in China and puts forward some enlightenment on college teaching in our country. Finally, the writer suggests the enlightenment of college education in China and its reference.
\end{abstract}

\section{Introduction}

Based on the development history of the international education trends, the paper introduces the origin and blossom of the inclusive education. It takes only several decades from its establishment to development, but the idea of the inclusive education has been widely understood and accepted by many countries which have put it into practice: UNESCO published World declaration on education for all; in 1994, UNESCO held World Conference on Special Needs Education at Salamanca, Spain and issued Salamanca Declaration; and in 2005, it released Guidelines for inclusion: Ensuring access to Education for All. However, few learners in China study the inclusive education except Professor Huang Zhicheng, Director of Institute of International and Comparative Education in East China Normal University, who made a specialized research on inclusive education and published Inclusive education: Attention on learning and participation of all students.

Though the inclusive education has been widely accepted around the world, opinions on it vary: domestic and foreign experts and scholars provide interpretations from different perspectives. On the basis of a more authoritative interpretation on inclusive education, the author proposes own views and understandings.

It can be seen from the previous researches that various countries regard the inclusive education as part of education and implement a series of theoretical researches and practices, among which the United Kingdom, the United States, Spain and Canada are particularly prominent. The paper focuses on the practices of inclusive education in Canada: the Government attaches importance to the inclusive education and develops related policies, implement the concept of inclusive education around all levels of society, pay attention to improve the faculty quality, and give financial support to the inclusive education. However, the author also raises existing problems worthy of attention, in order to better understand the follow-up study and carry out practices on the inclusive education.

Since the special education is still underdeveloped in China, it is a necessity for Chinese experts 
and learners to study and obtain experience on inclusive education from advanced countries while in turn the research results are likely to promote the development of inclusive education in China. At present, Chinese learners prefer to study researches on inclusive education from the United States, Britain and Japan rather than from Canada. However, as a diversified multi-ethnic country similar to China, the cultural education for both the countries shares more. Thus, this paper, by the study on inclusive education in Canada, aims to understand its development, status, characteristics and features, and learn from experiences and lessons during the development, further to enlighten the inclusive education in China.

\section{Concepts and background}

The idea of inclusive education stems from the unremitting pursuit of the education democratization and it was initially put forward for respecting the right of all who receive special education.

Through the review of previous studies on inclusive education in the past decade, it is easily found that there are several views on the origin of inclusive education: some scholars believe that "inclusive education directly originated in the Civil Rights Movement of the United States in 1950, further dating back to Renaissance and the social movements seeking for equality and freedom in The Enlightenment”. "These movements not only gave birth to the values of the western individual freedom and social equality, but also provided impetuses for people with special needs participating in social activities equally and for the origin of the special education.” (Deng et al. 1-7) Some scholars think that "inclusive education derives from the Integration of Education in 1970s, which was an education campaign in the field of Special Education.” (Qian et al. 32-34) The origin of this view was closely related to the development of Special Education. The development of international special education went through three major stages: (1) oriented by the medical model, it focused on the diagnosis and treatment; (2) leaded by psychology, it emphasized measurement; (3) the dominant model of classification and sociology advocated that every child had an equal right to receive education and opposed to isolate children with special needs in special schools.” (Huang 51-54) For the development of special education, the first two stages were traditional models with characteristics that children with special needs were isolated in special schools through diagnosis and classification by specialists and experts. Both the stages separated students with special needs from the normal people, with obvious phenomenon of the "existing exclusion" in terms of education and social integration. The third stage of the integration allowed children with special needs to enter the ordinary schools, which was the formalism. That is, the children with special needs had to follow the development of normal children, but their special needs were ignored, which was implicitly excluded. With the development of practices, the disadvantage of the integration education was recognized: it was not likely to achieve the common development between students with special needs and ordinary students, the former of who were still excluded.

The inclusive education is originated and developed under the trend of international education democratization, especially promoted and driven by the publicity of international education organizations, among which two international conferences on education played important roles. One was "World Conference on Education for All" at Jomtien of Thai in 1990, held by UNESCO and other international organizations, and World Declaration on Education for All was issued at this conference. The Education for All raised at the conference emphasized that education was a basic human right; education was extremely important for personal development and social progress, thus basic education must be popularized and equality in education must be promoted. The goal of Education for All is to meet the basic learning needs of all. Another was "World Conference on Education for Special Needs" at Salamanca of Spain in 1994 held by UNESCO and Salamanca Declaration was issued. The conference once again stressed that everyone had the fundamental right to receive education; each person had own unique characteristics, interests, abilities and learning needs, so schools should accommodate all children and meet their special educational needs. At the conference, the inclusive education was proposed at first time.

If the "World Conference on Education for All" in 1990 provided a stage for inclusive education, 
the "World Conference on Education for Special Needs" in 1994 was further to kick it off. By the end of the 20th century, researches on inclusive education has become blooming among the field of international education. Since then, the term "inclusive education" has also become the most popular educational vocabulary.

Although the term of "inclusive education" has been widely used around the world, the definition of inclusive education varies with little difference. The concepts of inclusive education given by scholars' home and abroad are shown as below.

The National Centre on Inclusive Education and Restructuring of the United States defines it as: to provide all students (including those with severe disabilities) with an equal opportunity to receive effective education; to train students to face the future life as a complete member of the society; and offer them enough assistance and support among the classes with similar ages in the nearest school.

The Centre for Studies on Inclusive Education in UK regards it as: inclusive education means with the appropriate help the disabled and the non-disabled children and adolescents can learn together at the ordinary schools. Inclusive means students should give full play to study, in order to enable all to participate in learning and activities at schools. Though the students' abilities and academic performances vary, they must come into the society after graduation to play their roles, therefore, the sooner for inclusive education, the more benefits for their integration into society.

Tomlinson, the Oxford scholar of the UK, believes that inclusive education refers to the inclusive education system, but it is unnecessary for students to stay in an integrated environment. "The concept of inclusive education raised by the Committee is not consistent with the concept that students should integrate with the mainstream.” (Daniel 8-10)

Tony Booth, the inclusive education expert in UK thinks that inclusive education is a process to strengthen student participation. He advocates that "students should participate in cultural, curriculum and community activities in the nearby areas and it is a process reducing exclusion." (Kong 1-5)

UNESCO defines inclusive education in the Guidelines for inclusion: Ensuring access to Education for All published in 2005: "inclusive education is a reflection process to increase the participation in learning, culture and community activities, reducing exclusion within and outside the education system, and meet the diverse needs of all learners. It aims to cover all children at school-ages with the faith to educate all children by regular system. Inclusive education involves educational content, approach, structure of education, changes and adjustments of educational strategies.” (Zhou 16-20)

Ainscow and miles reviews literatures related to inclusive education and found various forms to define the concept: (1) inclusive education is relevant to the disabled and special education needs; (2) it is against exclusion; (3) the inclusion focuses on all exclusive of vulnerable groups (4) aiming to promote everything at school; (5) it refers to the universal education. (Cox 12-14) These differences among definitions of inclusive education show that the agreement on issues that inclusive education should handle and on educational visions has not been reached.

UNESCO emphasizes in 2008, that inclusion is a progress to increase participation in education, training, cultivation and community meet diversified needs of learners. Meanwhile, it aims to separation and isolation at schools and in the society.

The above definitions of inclusive education are given from a macroscopic aspect, which is a nice, idealistic but impractical philosophy of education, which may take a long time to realize with hard work and extensive support. During the implementation, practices for inclusive education should be combined with its own specific cultural background and more effective policies to ensure that the majority of children can equally access to education. Under the philosophy of inclusive education, schools and the society may create an inclusive atmosphere to safeguard everyone's equal right to receive education; schools and the society should accommodate each member, especially in ordinary schools, an idea to accept all must be firmly established and better conditions may be gradually created to meet different needs of students. A key idea of inclusive education is to equally treat each one rather than pay over attention to certain students or neglects certain ones; it advocates attaching importance to each student and fairly treating them. That is, its purpose is to 
accommodate all, oppose discrimination and exclusion, promote active participation, focus on collective cooperation, and meet different needs.

Inclined to support the view proposed by the famous British scholar Mettler, Canadian learners believe that the inclusive education is the value that accommodate and encourage diversity resulting from genders, nationalities, races, languages, social backgrounds, educational levels and disabilities. (Len and Felicity. 15.) It is the reason that the inclusive education involves in all members in the community.

Researchers in Canada define it between two extreme views. "Some scholars insist that, under the ordinary educational system, all students should be provided with all assistance and support in any stage to get opportunities for success. Others think that school structures should be changed, and then it is unnecessary to provide so-called 'special' support, in which way students who have special needs or learning-disabled students are likely to enjoy the same support......"

Different from the both views, scholars in Canada put forward a new definition between the two views: during the education at ordinary schools, students who have difficulties in learning, intelligence, physicality, listening and sensation "can accept instruction after school, and they have the same opportunity to study at school as long as they can follow the syllabus.” The understanding of inclusive education given by Canadian scholars is that students with special needs at ordinary schools can obtain special assistance and support so that they can have regular courses in normal classes.

\section{Philosophy and current development characteristics for inclusive education in Canada}

It is known that as a subsystem of culture, education not only bears responsibility of cultural inheritance, but also upgrades culture during the inheritance. So issues on education should be analyzed from the relationship and the mutual influence between education and culture. (Zhang 6) Multicultural education refers to the education among different cultures of ethnic and races, and the education for different social classes, communities, groups and individual. It is an inevitable requirement for democratization education that all students have the right to learn together; and the segregated education is established in the name of protecting the disabled and students with learning difficulties. The general students and those with special needs are educated respectively in general education and special education systems. Multicultural education in Canada is to seek cultural equality, and students with special needs should not be in disparate treatment, just as people of different races, classes and cultural backgrounds should not be in disparate treatment.

\subsection{Providing perfect policies for special education}

The provincial government is responsible for expenses of children with special needs to study. Generally, the budget funds of the provincial government are mainly three parts: daily costs, special funds and expenses for capital construction. For example, in order to support the development of teaching by adequate means and coordinate the entire education system and engagement in advanced studies, Alberta developed a five-year teacher training program in 1980 to expand teachers and funds for special education under the premise of increasing expenditure, further to meet needs of special education.

\subsection{Developing special education}

In Canada, parents may enter into the partnership with educators and other staff, which plays a key role in educating their children with special needs. Engagement in special education under the philosophy of inclusive education is bound to take the society resource into account and it must obtain the focus of the whole society. All high school students in Canada, including the disabled, must put knowledge studied at school into practice. In the provincial public education system, in addition to receiving classroom teaching, students over 14 years old should go to work according to the social needs. Research institutions, families, schools, government agencies, community groups, health professionals, and universities are more or less associated with special education, so the communication and cooperation among them is the key to enhance the development of special 
education. Some schools may cooperate with local communities, businesses or factories to build a long-term stable relation, in order to provide living and learning experience for students with special needs, by means of which to develop and train vocational skills of students with disabilities.

\subsection{Implementing the philosophy of inclusive education}

During the development of inclusive education in Canada, scholars pursue a positive concept: "Every student has the right to participate in all activities at schools; each student is entitled to take part in regular teaching activities and individual needs should be met. If the special needs cannot be satisfied under normal circumstances, the courses may be changed to meet the needs after regular classes; all students should be divided into groups according to ages so that it is a convenience for them to participate in schools activities." The philosophy of inclusive education occurs in the field of early education in Canada, and becomes flourishing along with the development of preschool special education. Special children not only can receive early identification and early intervention, but can enter into ordinal kindergartens to play and study with normal children. In Canada inclusive education of pre-school level is becoming increasingly common.

The philosophy of inclusive education in Canada emphasizes focusing on students and meeting the needs of students in the course of development and practices, and promoting and realizing an authentic inclusion, so that all students with special needs can obtain a round development in such an environment. Key points for inclusive education in Canada are in the following: "The concept of inclusion is reflected in all management echelon; the policies and budgets of inclusive education are fully supported by the provincial legislation, standards and guidelines; curriculum changes; parents participate in decision-making; it should have teacher training and professional development, etc.”

In addition, the specific circumstances of different provinces require certain flexibility in policy-making and legislation: "Local jurisdictions and schools are entitled to have power of interpretation on policies and legislation, thus to meet the regional and local needs." Such policies not only allow local governments and schools to interpret in line with actual situations during developing inclusive education, but also are featured with great flexibility which is conducive to the sound development of regional inclusive education. A unique characteristic of inclusive education has been formed during its development in Canada, which is the achievement given by the central government, local governments, legislation and support from all aspects. The power of interpretation authorized by the Government and legislations can ensure the combination between inclusive education and actual situations, so as to develop it with a distinguishing feature.

At the primary stage in Canada, the elementary schools in Halifax, for example, may discriminate the language proficiency of children for enrollment, and evaluate and train the ability to speak of students at all ages, which is responsible by language teachers and extracurricular instructors. In Alberta, students with special needs may go to school under the help of funding, or receive instructions after school, so that they can complete the homework at school. In addition, "it is stipulated in Ontario and Newfoundland that if the disabled fail to enter into a school in certain district, they can apply to study in another school district or in another province.” (Chen 27)

\subsection{Providing legislative guarantee}

Being in the northern of North America and one of the advanced industrial countries in the world, Canada is also one of the more developed countries in education. The enrollment number in universities and colleges, high and middle schools and primary schools is one fifth of the population, and the per capita education-year is 11.3 to 12.5 years. The eleven-year compulsory education is carried out around the country and the minimum age to leave school is 16-year-old. It was said in a report made by the World Organization for Economic Cooperation and Development (OECD) in 1976 that Canadian education had been in the leading position in 1970s. Meanwhile, inclusive education has been gradually understood and supported by the public in Canada. Canadians began to focus on educational equality, since they laid emphasis on issues related to the values and multiculture in Canada.

It is specified in Canadian laws that education is the responsibility of provincial and local governments, thus there is no Ministry of Education in the federal government to manage national 
educational institutions, but it does not mean that the federal government has nothing to do with education. On the contrary, there are many departments in the federal government in charge of carrying out special education and supporting general education. The provincial government is established to manage educational issues in each province.

In term of education administration in Canada, the biggest feature is the local and provincial responsibility system of highly decentralization of authority. As early as the first constitution British North America Act was formulated in 1867, the governors took into account the factor of bilingualism and multiculture and believed that education system should not be in severe management; therefore, it is expressly stipulated in Article 93: every provincial parliament and local government is entitled to make educational policies; education is the responsibility of the provincial and local government; the provincial Ministry of Education shall be established to in charge of education.

The main part of the Constitution in 1982 is Canadian Charter of Rights and Freedoms, which involves in the disabled children and their family. Then schools and authorities began consciously realized that special education was not a charity but requirements of law. Schools started consciously to reexamine its educational system and plans whether it broke the rule that "the laws protect the equal rights that everyone shall enjoy", and immediately corrected illegal phenomenon such as separating the disabled students from ordinary education.

Under the influence of constitutional amendments, all provinces and regions in Canada had modified their education acts by the end of the late 1980s, mostly providing educational opportunity for children with disabilities.

In 1988, the Canadian Parliament passed the famous Canadian Multiculturalism Act which "accept all Canadians as the full and equal participants in the society." (Li 53) Educational legislation fully realizes that all Canadian citizens have right to receive education and enhances the stability of Canada's multicultural society.

It is stated in the Section Six of School Act that all students have the right to learn in a safe and good atmosphere. Students with special needs should receive prompt attention; it is necessary to make comprehensive assessment on their needs, judge their merits and find out their demands before making proper educational programs for them. Students with special needs should follow the education programs and the process of formulation and evaluation. To some extent, all students with special needs are expected to participate in these programs. In addition, students shall observe school regulations, code of conduct made by local education committee $s$ and other rules and regulations.

For example, the Ministry of Education in British Columbia had established an educational policy advisory committee consisting of representatives of business departments, students, education administrators, parents and delegates of multicultural and ethnic organizations. In terms of issues on education policies, the committee held an extensive consultation with all walks of life to understand special requirements of education from various organizations, institutions and citizens. On this basis, the Ministry of Education modified and amended the educational policies. In 1979, it was required in the School Act, that each school district should "provide appropriate educational environment for all of the right age for free”. Since the Canadian Charter of Rights and Freedoms took effect in 1985, the rights of children with special needs to receive general education have been further guaranteed.

\subsection{Increasing educational expenditure}

Each provincial Ministry of Education is responsible to allocate funds for the special needs programs and services, and together with the local Board of Education to complete the objectives established by the education system: providing good education opportunities for students with cost-effective; appropriately adjusting the relevant aspects developed by the Ministry of Education such as the curricula, the ancillary resources for study and the appraisal procedures. The guidelines formulated by the Ministry of Education must ensure fairness and rationality with appropriate standards, and it has an important responsibility in terms of providing programs and services for 
students with special needs in particular.

The funds for special education are distributed to every school district by each provincial Ministry of Education in Canada according to its and goals and target. Taking the province of British Columbia as an example, the specific figures of funds are determined by the three factors below: (1) the basic education funding for each school district is 280,000 CAD and the educational grants is $3,943 \mathrm{CAD}$, the total of which is $283,943 \mathrm{CAD}$; (2) the average special education funding depends on the number of students identified by the school district, and the identification is confirmed by the percentage of the quantity of students with special needs in total student number in the school district; (3) the fund amount for other services is determined by the number of students who receive the services in the school district. The supplementary funds of special education for educational goals and targets are in charged by each provincial Ministry of Education. All measures are taken to ensure that the funds are used on the services for benefiting children with special needs. The funds cannot be misappropriated; on the contrary, other expenditure can be applied to the special education work.

In addition, each provincial Ministry of Education in Canada also attaches importance to increasing investment in equipment and facilities, further to meet needs of children with various special needs children who should receive rehabilitation training and special education. The classrooms equipped with special education resources, including teachers and teaching assistants, are set up in these schools receiving the disabled children. If the students with special needs cannot be satisfied in ordinary class, they may be placed in classroom with special resources, where they can use various facilities, get the individualized counseling, and meet their own needs by special modern means. None is dispensable that establishing resource teachers, possessing and implementing individualized teaching plans.

\subsection{Providing faculties}

"In Canada, the general teacher education bears responsibility of training special education teachers. Many universities set the curricula for special education, which is a required course for normal major. Since the special education is part of education major, students who want to engage in special education must obtain the educational bachelor's degree and receive one-year training on methods and skills of special education. Then they can mount guard after getting the qualification. " (Xie 46) Besides, some special programs including consulting, school psychology and trainings for special education are launched in some universities.

Specialized institutions are established in each province to provide training and assistance for special education teachers and staff. For example, in British Columbia, institutions and organizations such as with teacher training schools, the school district's organizations, non-governmental organizations and parent's aid agencies are set up. Some of the expenditure for these institutions is from the budget of the school training funds, the other from the special education fund aided by the provincial Ministry of Education.

The University policy for Teachers in British Columbia was published on June 18th of 1999. It is particularly pointed out that during implementing regular teaching programs, special education shall be covered, which can provide continual opportunities for integrating teachers and students with special needs and also requires all teachers should understand the different needs of special students. Thus, it is one of the essential requirements to realize the idea of inclusive education that possesses a high-quality team with all necessary skills.

\section{Deficiencies for inclusive education in Canada}

Facing the challenges brought by inclusive education, teachers in traditional education system must adapt to new roles. However, during the practice of inclusive education in Canada, teachers have not received adequate effective training. Researches show that only $26 \%$ of teachers who teach the disabled in inclusive education system have received in-service training. Deficient training results in inadequate capacity to settle matters in inclusive education. 


\subsection{Insufficient resources and supports}

A survey shows that $77 \%$ of teachers think they do not have enough time to provide appropriate assistance and support for students who have difficulties and with special needs. They want additional help from others and it is necessary for them to communicate with special teachers.

\subsection{Ambiguous fund allocation limits}

In some provinces, there is no clear and specific boundary for education funds. It means that fund for students with slight disabilities and for gifted children are both in basic education resources. When determining who have the priority to use the funds, a number of committees and private schools may not allocate it to those with special needs. Funds and financial allocations are not used in right place, which causes difficulties in practice of inclusive education.

\section{The enlightenment of inclusive education on China's college teaching}

Inclusive education has been put into practice for years in foreign countries. And there is much experience worthy of learning and reference. For example, during the implementing inclusive education, effective measures and actions rather than theories are carried out. However, in China there are no relevant policies of inclusive education to be made, which is not conducive to carry out inclusive education widely and smoothly. The key for transformation is to change the idea; when the concept has been changed, other aspects may be readily solved. Therefore, laws and regulations of inclusive education should be developed as soon as possible, in which way to interiorize the philosophy of inclusive education in China and to create a matching educational system, aiming to ensure the implementation of inclusive education. In other words, it is a necessity and urgency to formulate policies, laws and regulations of inclusive education with Chinese characteristics. Only in this way, the full implementation of inclusive education in China is possible.

The basic concept of inclusive education is to "strengthen the equitable participation and reduce the exclusion", which centers on ordinary students and the disabled, the excellent and the poor, and students from urban and rural. In addition, it should also provide a variety of free choices for students.

1) Changing the mode from the teacher-centered to the student-centered

The internal causes serve as the basis for the change of a thing while the external factors provide the condition, thus the internal cause is decisive. Teaching is the external factor while learning is the internal cause, so students must be oriented. As the masters of learning activities, students are irreplaceable in the course of obtaining knowledge and developing intelligence and abilities. Teachers are unable to learn and think instead of students, and knowledge and ideas cannot be forced into students' brains. Therefore, changing the mode from teacher-centered to student-centered is to transform from positive learning to active study.

Students should actively raise questions. As an ancient saying goes that learning roots in thinking while thinking originates from doubt. Thinking generally comes from doubts. It is an important means and process to train students from raising a question, analyzing and solving it by themselves. A question proposed by student is likely to be better than by teacher.

Teachers should regard students as the initiative explorers and guide them to solve problem after raising it. On this basis, teachers should give much more time for students to think and raise doubts to interest students, which can lead thinking of students to an active state.

The mode of "leading by teachers and centering on students" is to allow students to change from "want them to study" to "they want to study". By the task-based approach, teachers can assign tasks to students and provide some clues, and students can take the initiative to explore, study and discuss in groups, to ensure that every student can participate in the teaching and learning.

2) Ensure the equality of teaching and of receiving education

Teachers must treat each student equally. Students of different looks, genders, nationalities, origins, backgrounds, intelligence, personalities and with different relations must be treated without discrimination. There are no preference, favoritism and physical discrimination for students with 
disabilities or those lagging behind; students' personalities cannot be violated and every student must be respected. All students of different levels must be taken care alike. Teachers should pay attention to the learning needs of every student and take care of each one as much as possible. Based on the diversities, teachers can good use of resources to help and cooperate with each other.

\section{Conclusion}

In conclusion, the inclusive education in Canada has been made achievements with unique characteristics in its development and practices. Therefore, researches on the inclusive education in Canada are of great significance to that in China.

It is difficult to simply and easily compare special education in China and Canada due to the different social systems, different cultural backgrounds and different national conditions. However, much experience about the special education in Canada is indeed worthy of learning. It can be seen from the researches on Canadian inclusive education that China there are still gaps on special education between China and the developed countries. The inclusive education is greatly supported in China, and there are some areas to carry out experiments of inclusive education. However, insufficient researches result in the poor scales in China, which are significantly different from some developed countries. Therefore, it is an urgency to further strengthen researches on inclusive education, in order to promote the development of inclusive education in China.

Strengthening researches on inclusive education and promoting the practices of inclusive education is important for the implementation of quality-oriented education in China. In the times of fierce competition, how to focus on equality and cooperation, and to improve the overall quality of education are the topics to be studied.

Due to the limited theoretical knowledge and related practice, there are certain deficiencies in the paper, including the theoretical research not deep enough, and some incomprehensive and immature views. Besides, there are some difficult problems to be solved. Thus, the author is eager for some guidance and instruction from professionals to better future study and work.

\section{References}

[1] Cox C, inclusive and inclusive society. What can we do and promote from educational workshop on inclusive education, Latin America, the Andean and southern cone, Buenos Aires, Argentina. 2009 (6): 12-14.

[2] Barton L, F. Armstrong. Policy, Experience and Change: Cross-Cultural Reflections on Inclusive Education [M]. London: Springer, 2008.

[3] Harry Daniels. Special Education Reformed: Beyond Rhetoric? London: New York: Farmer Press.2000, 8-10.

[4] Inclusive Policy and Practice in Education: Best Practices for Students with Disabilities [EB/OL]. The Roeher Institute.

[5] http://www.inclusiveeducation.ca/documents/BEST—PRACTICES.pdf, 2004-04/2017-05-01.

[6] Quoted from Richler, Diane. UNESCO: 2005 EFA Monitoring Report-Commissioned Study Quality Education for Persons with Disabilities[EB/OL]. http://unesdoc.unesco.org/images/0014/001466/146694e. pdf Retrieved May 1, 20176

[7] Inclusive Policy and Practice in Education: Best Practices for Students with Disabilities[EB/OL]. The Roeher Institute. http://www.inclusiceeducation.ca/documents/BEST-PRAVTICES.pdf,2004-04/2017-05-02 